\title{
Comparison of Elemental Anomalies Following Implantation of Different Cell Lines of Glioblastoma Multiforme in the Rat Brain: A Total Reflection X-ray Fluorescence Spectroscopy Study
}

Karolina Planeta, "Z Zuzanna Setkowicz, " Natalia Janik-Olchawa, Katarzyna Matusiak, Damian Ryszawy, Agnieszka Drozdz, Krzysztof Janeczko, Beata Ostachowicz, and Joanna Chwiej*

Cite This: ACS Chem. Neurosci. 2020, 11, 4447-4459

Read Online

ABSTRACT: Glioblastoma multiforme (GBM) is a primary brain tumor with a very high degree of malignancy and is classified by $\mathrm{WHO}$ as a glioma IV. At present, the treatment of patients suffering from GBM is based on surgical resection of the tumor with maximal protection of surrounding tissues followed by radioand pharmacological therapy using temozolomide as the most frequently recommended drug. This strategy, however, does not guarantee success and has devastating consequences. Testing of new substances or therapies having potential in the treatment of GBM as well as detection of their side effects cannot be done on humans. Animal models of the disease are usually used for these purposes, and one possibility is the implantation of human tumor cells into rodent brains. Such a solution was used in the present

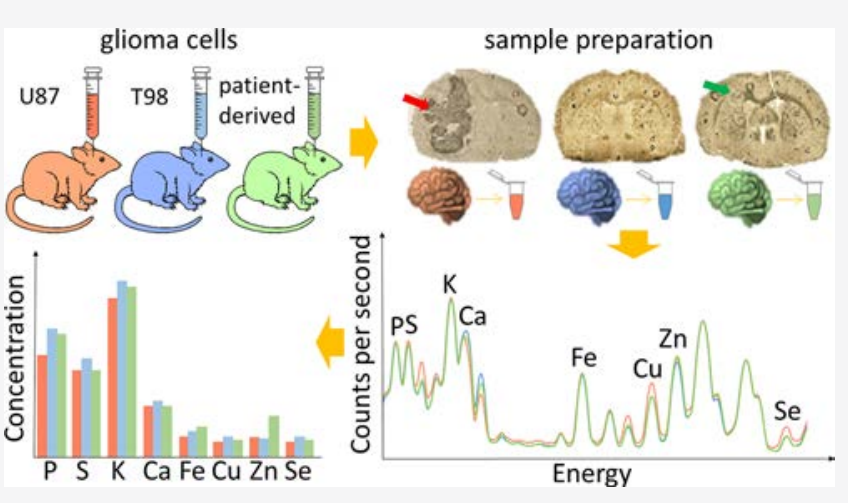
study the purpose of which was comparison of elemental anomalies appearing in the brain as a result of implantation of different glioblastoma cell lines. These were two commercially available cell lines (U87MG and T98G), as well as tumor cells taken directly from a patient diagnosed with GBM. Using total reflection X-ray fluorescence we determined the contents of $\mathrm{P}, \mathrm{S}, \mathrm{K}, \mathrm{Ca}, \mathrm{Fe}, \mathrm{Cu}, \mathrm{Zn}$, and Se in implanted-left and intact-right brain hemispheres. The number of elemental anomalies registered for both hemispheres was positively correlated with the invasiveness of GBM cells and was the highest for animals subjected to U87MG cell implantation, which presented significant decrease of $\mathrm{P}, \mathrm{K}$, and $\mathrm{Cu}$ levels and an increase of Se concentration within the left hemisphere. The abnormality common for all three groups of animals subjected to glioma cell implantation was increased Fe level in the brain, which may result from higher blood supply or the presence of hemorrhaging regions. In the case of the intact hemisphere, elevated Fe concentration may also indicate higher neuronal activity caused by taking over some functions of the left hemisphere impaired as a result of tumor growth.

KEYWORDS: glioblastoma multiforme, GBM, animal model of GBM, bulk elemental analysis of brain, total reflection X-ray fluorescence, U87MG, T98G

\section{INTRODUCTION}

One of the most common primary brain tumors are gliomas, which usually develop from glial cells, non-neuronal cells supporting the functions of neurons. As different types of glial cells exist, various types of gliomas are distinguished, ${ }^{1}$ but the most aggressive is glioblastoma multiforme (GBM), which accounts for about $54 \%$ of all glioma cases and represents about $16 \%$ of all brain tumors. The World Health Organization classified GBM to cancers with the highest (IV) degree of malignancy. $^{2}$

Despite various therapies, median survival of patients suffering from GBM is $14-16$ months and only $9.8 \%$ of them survive 5 years. $^{2}$ The high aggressiveness of GBM results from its complex nature, which includes the presence of necrotic and hemorrhagic regions or cellular atypia within the same tumor mass. GBM has high infiltrative potential and vascular proliferation ability, which lead to its great invasiveness. ${ }^{3}$ Standard glioblastoma treatment includes surgical resection of the tumor, radiotherapy, and chemotherapy, usually based on temozolomide (TMZ). Despite such radical therapy, there is no significant improvement in the patient survival rate. The location and infiltrating nature of the tumor prevent its total resection and make precise radio-

Received: October 9, 2020

Accepted: November 9, 2020

Published: November 18, 2020 
Table 1. Limits of Detection and Intraday and Interday Precision Values Obtained for Analyzed Elements

\begin{tabular}{|c|c|c|c|c|c|c|c|c|}
\hline parameter & $\mathrm{P}$ & $\mathrm{S}$ & $\mathrm{K}$ & $\mathrm{Ca}$ & $\mathrm{Fe}$ & $\mathrm{Cu}$ & $\mathrm{Zn}$ & $\mathrm{Se}$ \\
\hline LOD (SD) $[\mathrm{ppm}]$ & $12.96(0.45)$ & $8.32(0.29)$ & $4.41(0.16)$ & $1.832(0.072)$ & $0.1916(0.0082)$ & $0.0852(0.0035)$ & $0.1078(0.0042)$ & $0.0297(0.0011)$ \\
\hline $\begin{array}{l}\text { intraday precision } \\
{[\%]}\end{array}$ & 2.0 & 1.6 & 1.0 & 3.1 & 0.3 & 0.7 & 0.2 & 4.9 \\
\hline $\begin{array}{l}\text { interday precision } \\
{[\%]}\end{array}$ & 1.3 & 1.2 & 0.7 & 2.8 & 0.3 & 0.4 & 0.2 & 1.2 \\
\hline
\end{tabular}

a)

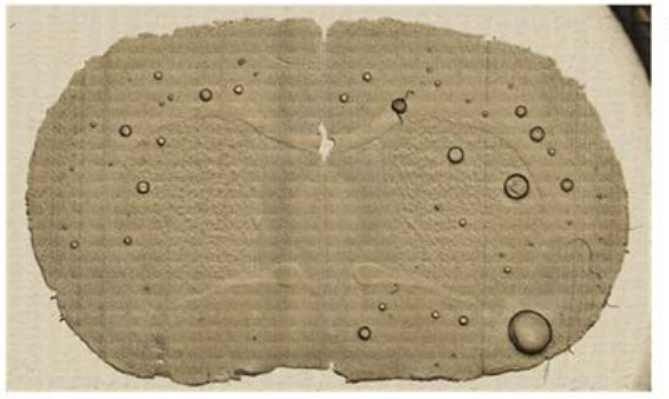

c)

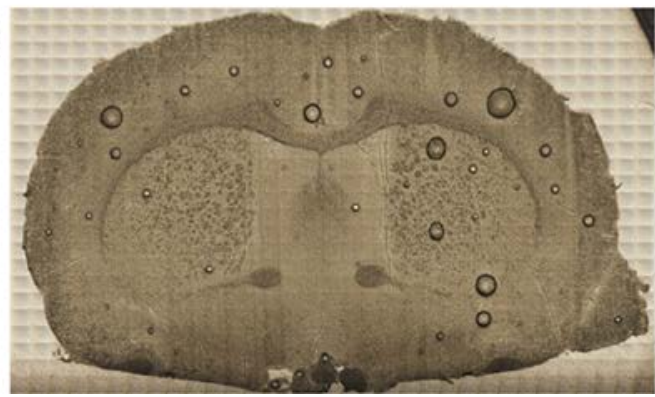

b)

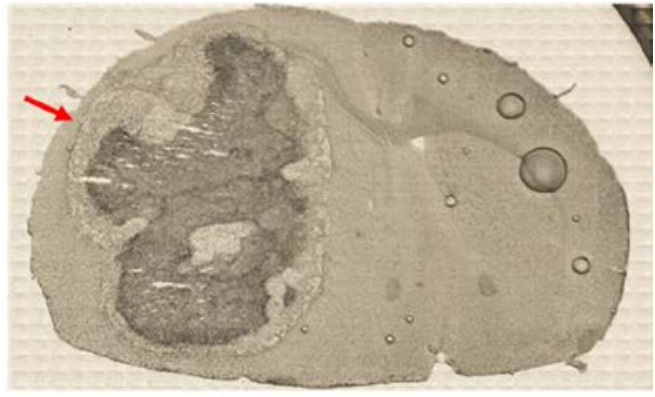

d)

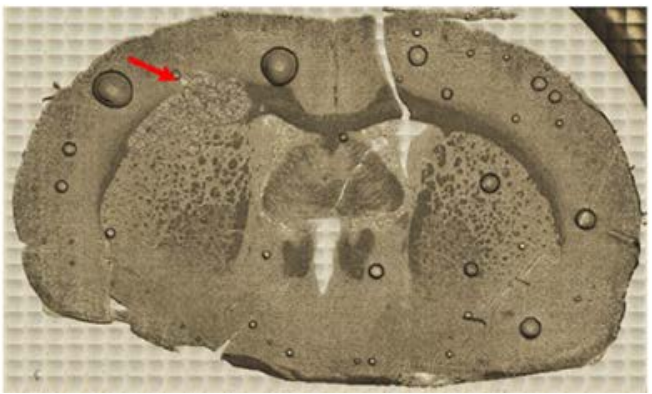

Figure 1. Microscopic images of unstained tissue slices taken from animals representing N (a), U (b), T (c), and P (d) groups. N group consisted of naive controls, while animals from groups $\mathrm{U}, \mathrm{T}$, and $\mathrm{P}$ were subjected to implantation into the brain of U87MG, T98G, and patient tumorderived cells, respectively. Red arrows indicate developed tumor mass.

therapy difficult. In addition, its complexity and drug resistance capacity reduce the effectiveness of the treatment. ${ }^{4}$ Due to lack of satisfactory results in the treatment of patients diagnosed with glioblastoma, new therapeutic strategies are still being sought.

To get better knowledge about tumor pathogenesis and progress, as well as to examine new therapeutic strategies before clinical trials, animal models of tumors are used. ${ }^{5-9} \mathrm{~A}$ wide range of GBM animal models are available. Some are based on implantation of human cells from established tumor cell lines into animal brains. There is also possibility to implant tumor cells taken directly from a patient diagnosed with tumor. In both approaches, immunodeficient and immunosuppressed rodents are usually used as experimental animals. ${ }^{8,9}$ As there is no one model that ideally reflects the nature of a human brain tumor, different models have been verified in order to assess their usability in preclinical studies. ${ }^{10-12}$

The existing literature shows that trace and minor elements may be involved in the pathogenesis and progress of different types of tumors. Bobko et al. indicated the significance of inorganic phosphorus for the metabolism of tumor cells, as well as the increased phosphorus demand by these cells associated with tumor growth. ${ }^{13}$ Duan et al. found that sulfur inhibits proliferation of cells separated from prostate cancer developed in vivo in nude mice ${ }^{14}$ while Eil et al. observed that immune response of tumor cells may be suppressed by high potassium levels. ${ }^{15}$ The information about the levels of elements in pathologically changed tissue may serve as tumor biomarkers and prognostic factors allowing prediction of patient survival or success of the anticancer therapy. ${ }^{16-19}$ The tissues taken from brain tumors were also analyzed with respect to the significance of different elements for pathogenesis and development of the tumor or to discover dependencies between elemental composition of the tumor and its malignancy grade. ${ }^{20-24}$

The aim of our research was to assess the elemental anomalies appearing in rat brain after intracranial implantation of different GBM cells. For the purposes of our experiment, we used two commercially available human GBM cell lines, namely, T98G and U87MG, and tumor cells taken directly from a patient diagnosed with primary GBM. Using the total reflection X-ray fluorescence (TXRF) method, we determined and compared the concentrations of $\mathrm{P}, \mathrm{S}, \mathrm{K}, \mathrm{Ca}, \mathrm{Fe}, \mathrm{Cu}, \mathrm{Zn}$, and $\mathrm{Se}$ in glioma-implanted and intact hemispheres of the brain. Each of 4 groups of animals ( 3 groups subjected to implantation of different GBM cells and normal rats) consisted of 6 individuals from which 2 brain hemispheres were taken, prepared, and measured separately. As a result 12 samples were examined per animal population. This study, aimed at the determination of elemental changes specific for particular GMB cell lines, is necessary to start the next steps of research focused on elemental modifications occurring in animal brains as a result of different new therapies.

\section{RESULTS AND DISCUSSION}

Limits of Detection and Precision. The limit of detection (LOD) and precision (intraday and interday) obtained using TXRF method were calculated for each 
examined element. As one can notice from Table 1, the lowest values of LOD were obtained for selenium (0.0297 ppm) and the highest for phosphorus (12.96 ppm). The values of detection limit are lower for elements with higher atomic numbers. The detectability of elements with the uses of XRF is influenced by the efficiency of detection of the fluorescent radiation emitted by the elements. This, in turn, strongly depends on values of radiation energy, which increase with element atomic number.

Values of intraday precision were good and varied from $0.2 \%$ to $4.9 \%$ for $\mathrm{Zn}$ and $\mathrm{Se}$, respectively. Interday precision values for all analyzed elements did not exceed $2.8 \%$.

Microscopic Evaluation. In order to define the degree of invasiveness of different GBM cells, before tissue digestion, microscopic images of the brain slices were taken from the area of implantation. The exemplary pictures obtained for the animals representing each of the examined groups are presented in Figure 1. As one can see, the implantation on U87MG cell line led to the development of massive tumor, which in the most severe cases included the whole hemisphere subjected to implantation (Figure $1 \mathrm{~b}$ ). Also after implantation of cells taken directly from a patient diagnosed with GBM, tumors appeared in rat brains (Figure 1d); however their volumes were much smaller than in case of U87MG cells introduction. For T98G cells, morphological changes of the brain were not visible or were limited only to the area of implantation (Figure 1c).

Spectral Analysis. As a result of TXRF measurements, for each analyzed brain hemisphere the $\mathrm{X}$-ray fluorescence spectrum was obtained. Energy calibration of the obtained TXRF spectra was carried out in the PyMCA program. The identification and quantitative analysis of $\mathrm{P}, \mathrm{S}, \mathrm{K}, \mathrm{Ca}, \mathrm{Fe}, \mathrm{Cu}$, $\mathrm{Zn}$, and Se were performed based on their $\mathrm{K} \alpha$ lines. As an example, the mean TXRF spectrum recorded for the left hemisphere of normal brain is presented in Figure 2. The $\mathrm{K} \alpha$ lines of the elements taken for further quantitative analysis are indicated with red arrows.

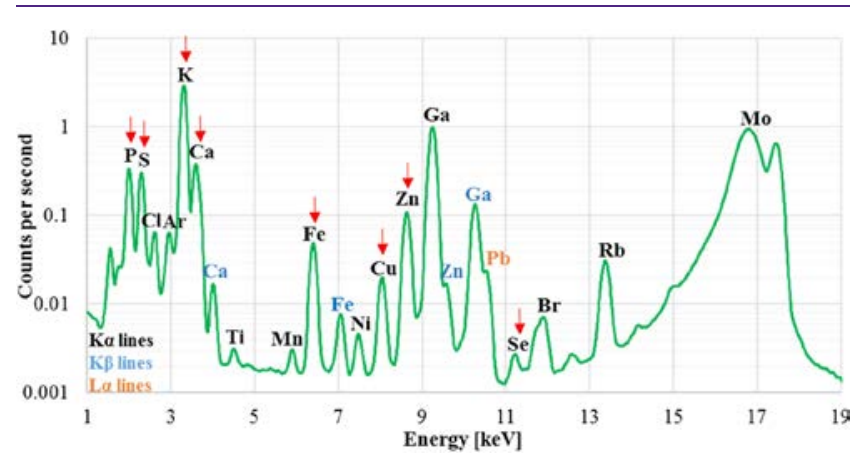

Figure 2. Mean TXRF spectrum recorded for left hemisphere of normal brain. The $\mathrm{K} \alpha$ lines of the analyzed elements (P, S, K, Ca, Fe, $\mathrm{Cu}, \mathrm{Zn}, \mathrm{Se}$ ) are indicated with red arrows.

Elemental Anomalies Introduced by Implantation of GBM Cells in the Left (Implanted) Hemisphere. To identify local elemental anomalies introduced by tumor development, the levels of $\mathrm{P}, \mathrm{S}, \mathrm{K}, \mathrm{Ca}, \mathrm{Fe}, \mathrm{Cu}, \mathrm{Zn}$, and $\mathrm{Se}$ in the left, glioma-implanted cerebral hemispheres were measured. Afterward, the median values of the concentrations were determined for each experimental group and together with the maximal and minimal values, as well as interquartile spans, they were presented as box-and-whiskers plots in Figure 3. To examine the significance of the observed anomalies, the $U$ Mann-Whitney test was applied. For all identified statistically relevant differences ( $p$-value $<0.05$ ) between animals subjected to GBM cell implantation and normal controls, $p$ values of the $U$ test are presented in Figure 3.

Many differences in the elemental composition of the left hemisphere were observed between animals subjected to glioma cell implantation and normal controls. However, it is not possible to indicate any elemental abnormality common for all animal models of GBM. As can be seen from Figure 3, implantation of U87MG cells led to a significant decrease of $\mathrm{P}$, $\mathrm{K}$, and $\mathrm{Cu}$ levels and an increase of Se concentration within the implanted hemisphere. In turn, the animals from the $\mathrm{P}$ group presented higher $\mathrm{Fe}$ and $\mathrm{Zn}$ contents and diminished Se level within the implanted hemisphere. The only difference compared to normal rats observed in animals subjected to implantation of T98G cells was the elevated Fe content.

Elemental Anomalies Introduced by Implantation of GBM Cells in Right (Intact) Hemisphere. The median values of elemental concentrations in right hemispheres were determined for each experimental group, and together with the maximal and minimal values as well as interquartile spans, they are presented in Figure 4. As can be seen, for all examined GBM models, the levels of iron within the intact hemispheres were elevated compared to the right hemispheres taken from normal rats. Additionally, for animals representing the $U$ group, lower concentrations of $\mathrm{K}$ and $\mathrm{Cu}$ and a higher concentration of $\mathrm{Ca}$ were observed. In turn, the rats subjected to patient-derived cell implantation presented only lower $\mathrm{K}$ levels within the intact hemispheres.

Differences in Elemental Composition between Implanted and Intact Hemispheres. In the charts presented in Figure 5, the concentrations of P, S, K, Ca, Fe, $\mathrm{Cu}, \mathrm{Zn}$, and $\mathrm{Se}$ in the left and right hemispheres were compared for individual animal groups. As can be seen, no differences between the elemental composition of two hemispheres were observed in normal rats. Such differences, however, were found in animals subjected to GBM implantation, and most of them were detected in animals subjected to implantation of the most invasive U87MG cells. They included lower levels of $\mathrm{P}, \mathrm{Ca}, \mathrm{Fe}, \mathrm{Cu}$, and $\mathrm{Zn}$, as well as higher concentration of $\mathrm{Se}$ in the implanted hemisphere. In rats representing $\mathrm{P}$ group, the implanted hemisphere was characterized by higher content of $\mathrm{Zn}$ and lower content of Se. In turn, in the left hemispheres taken from animals subjected to T98G cells implantation, lower contents of $\mathrm{S}$ and $\mathrm{K}$ were observed.

Discussion. The aim of our investigation was to assess the effects of GBM cells implanted in a rat cerebral hemisphere and of their further development on the elemental composition of the whole brain. The study was carried using two commercially available cell lines (U87MG and T98G), as well as tumor cells taken directly from a patient diagnosed with GBM. The degree of aggressiveness of the tumor developing from different GBM cells strongly differed and was the greatest for U87MG cell line. The intensive tumor growth and deteriorating condition of the animals representing the $U$ group led to the decision about the earlier experiment termination.

Corresponding brain hemispheres taken from the experimental and control animals were compared regarding concentrations of elements. In addition, differences in the elemental composition between the implanted and non- 

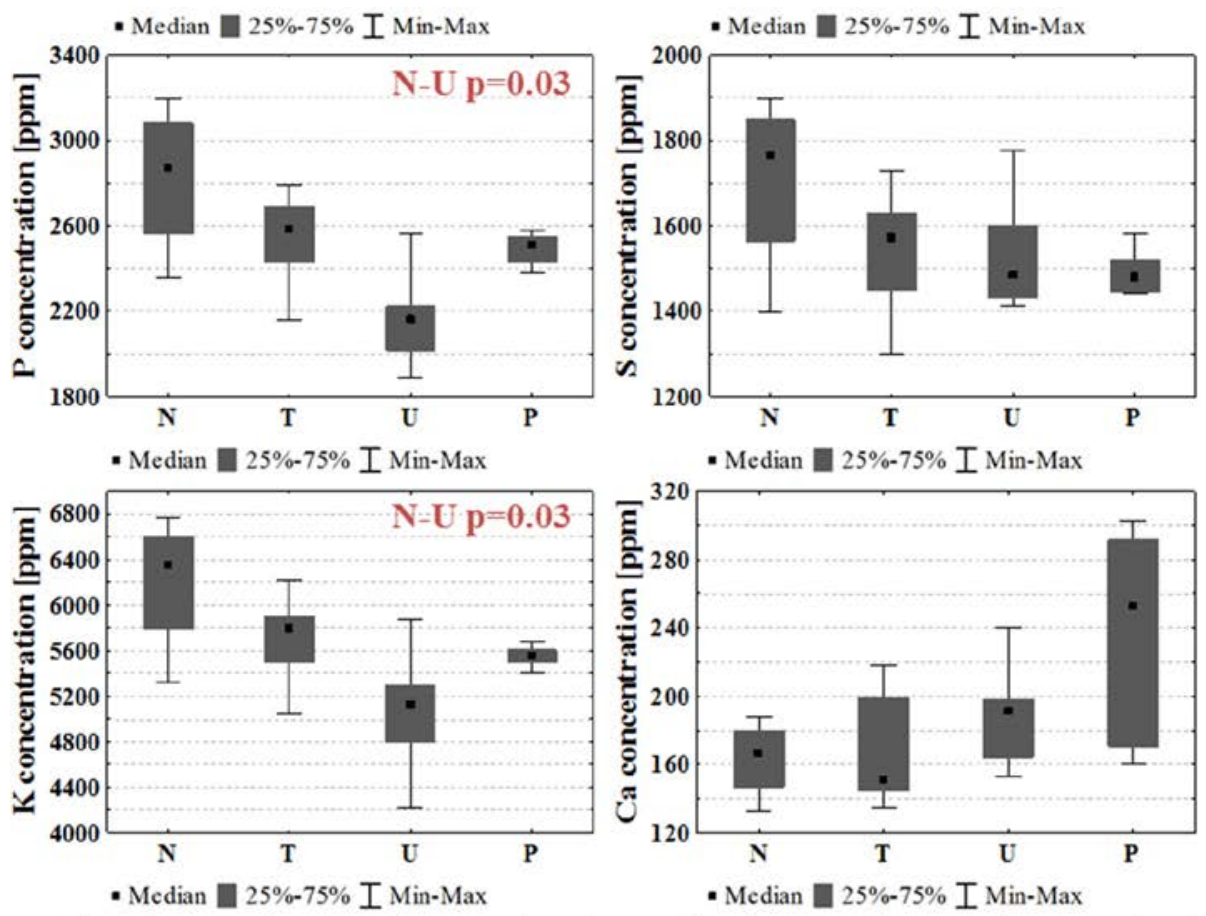

- Median 25\%-75\% I Min-Max
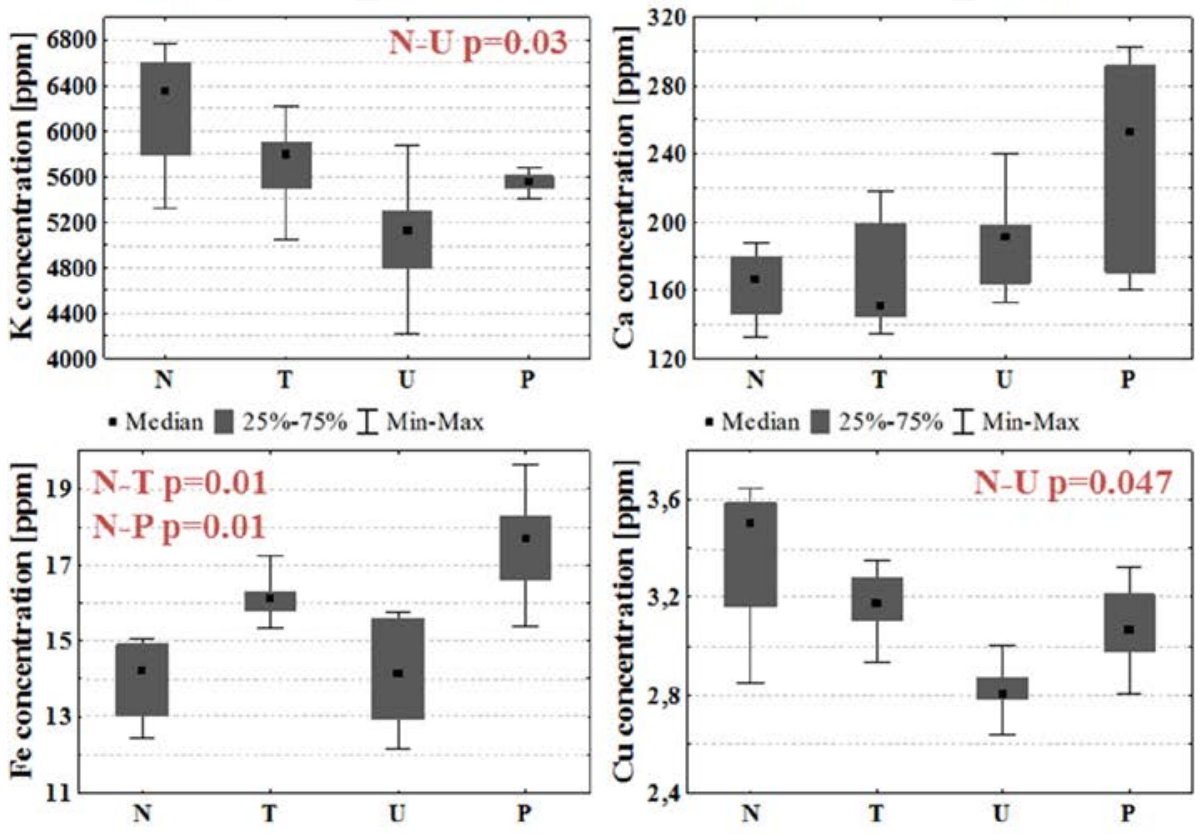

- Median $25 \%-75 \%$ I Min-Max

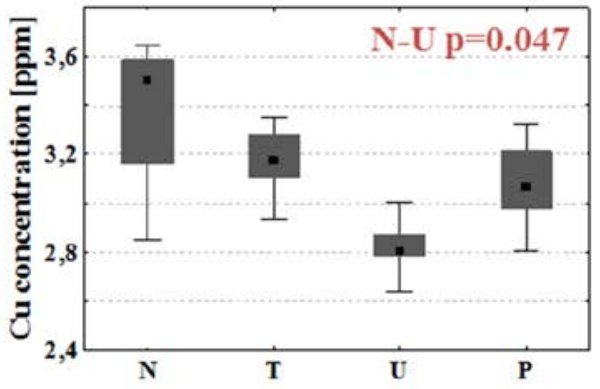

- Median $25 \%-75 \%$ I Min-Max

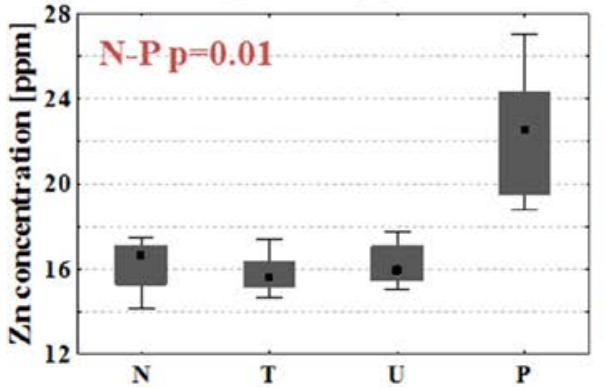

- Median $25 \%-75 \%$ I Min-Max

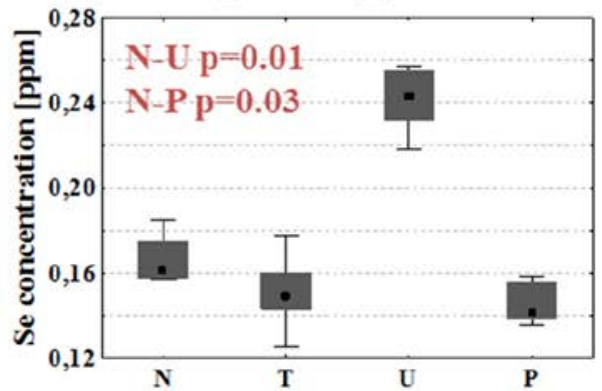

Figure 3. Median, minimal, and maximal values, as well as interquartile spans (gray boxes), of elemental concentrations in the left hemispheres of brain for N, T, U, and P groups. The statistically significant differences ( $p$-value $<0.05$ ) between animals subjected to GBM cell implantation and normal rats are marked in red.

implanted hemispheres were evaluated for each animal group. The concentrations of $\mathrm{P}, \mathrm{S}, \mathrm{K}, \mathrm{Ca}, \mathrm{Fe}, \mathrm{Cu}, \mathrm{Zn}$, and Se were determined using the TXRF method. To prove the usefulness of this method for the elemental analysis of examined samples, validation parameters such as LOD and precision were determined. The obtained LOD values were low and varied from $0.0297 \mathrm{ppm}$ for Se to $12.96 \mathrm{ppm}$ for P. The precision of performed measurements was very good, and for most of the analyzed elements, intraday precision did not exceed $4.9 \%$, while interday precision was no more than $2.8 \%$.

For all examined experimental groups significant elemental anomalies were observed in both implanted and intact brain hemispheres; however the most changes were found for rats subjected to implantation of the most invasive U87MG cells. The smallest differences in elemental composition occurred for animals implanted with T98G cells, which confirms the manufacturer descriptions of the used commercial cell lines, where U87MG cell line was defined as tumorigenic while T98G was defined as nontumorigenic. According to our best knowledge, this is the first study where elemental anomalies occurring within the brain as a result of glioma cell implantation were analyzed. Therefore, in the discussion we confronted our results with literature data obtained for samples of both human and animal origin and concerning the elemental anomalies associated with malignant brain tumors. The reviewed studies were not based on bulk elemental analysis 

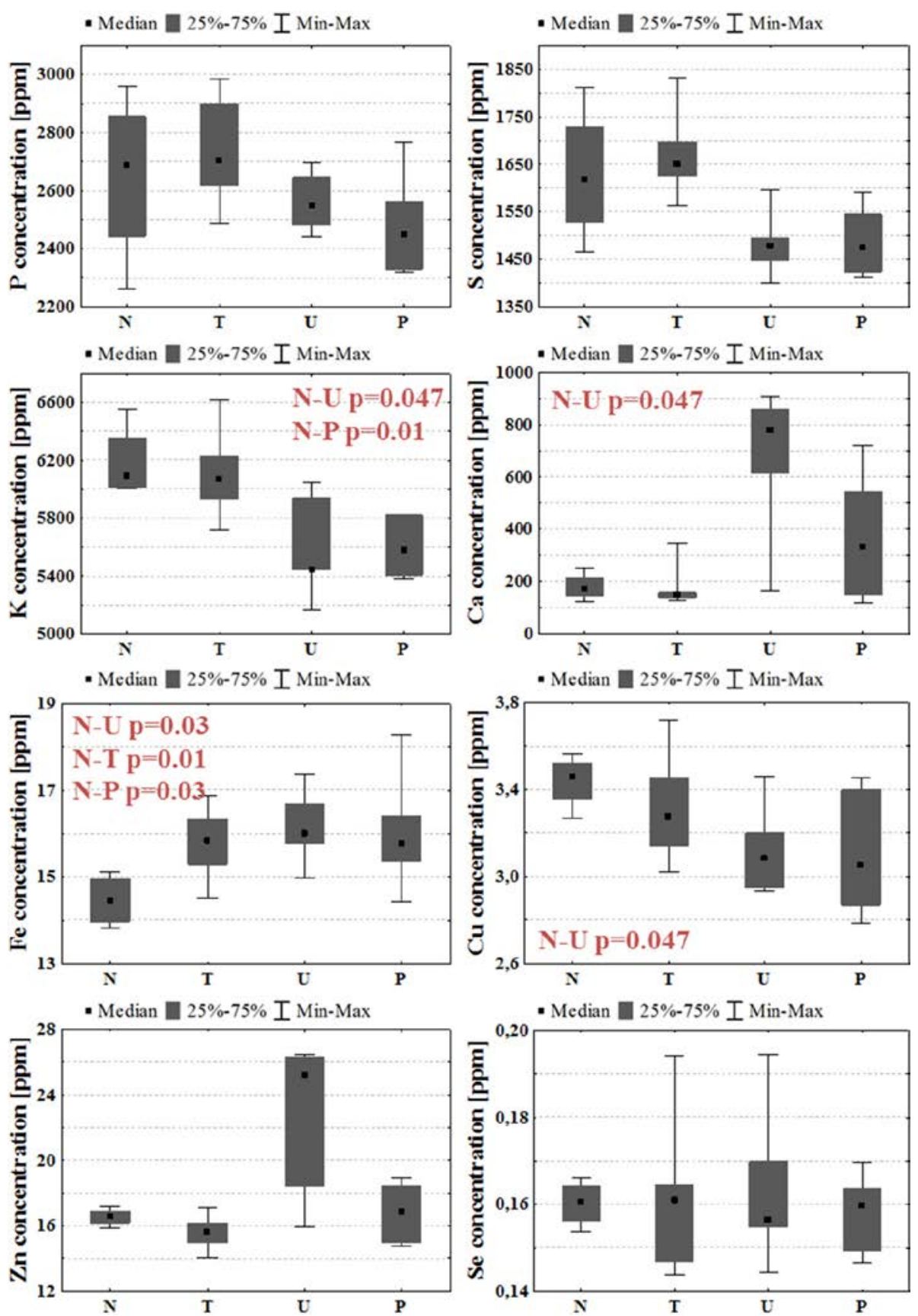

Figure 4. Median, minimal, and maximal values, as well as interquartile spans (gray boxes), of elemental concentrations in the right cerebral hemispheres for N, T, U, and P groups. Statistically significant differences ( $p$-value $<0.05$ ) between animal groups subjected to GBM cell implantation and normal rats are marked in red.

of the brain hemispheres, but concerned either the comparative analysis of tumor and normal tissue or the topographic elemental analysis of the brain affected with tumor. We also discussed the significance of the analyzed elements for the pathogenesis, progress, and treatment of GBM.

Phosphorus is a mineral the presence of which in body cells is crucial for their proper functioning. It constitutes a building component of nucleic acids, phospholipids, or phosphoproteins. Being a part of ATP, phosphorus plays a key role in energy metabolism processes. $^{25}$ It is also involved in cell signaling through phosphorylation reactions, which regulate activity of many types of enzymes. ${ }^{26}$ Already in the mid- twentieth century, there were reports of increased uptake of radioactive phosphorus by malignant brain tumor cells. ${ }^{27}$ It has been shown that compared to normal brain tissue, tumor tissue was characterized by diminished phosphorus concentration. This observation was correlated with a simultaneous decrease in phospholipid (cephalin, lecithin, and sphingomyelin) content in cancer tissue. ${ }^{28}$ Based on conducted MR examinations Hubesch et al. observed that the content of phosphate metabolites (phosphomonoesters, phosphodiesters, and phosphocreatine) in brain tumor was decreased compared to a normal human brain. ${ }^{29}$ From the other hand, Srivastava et al. revealed an increased phosphatidylcholine level in brain tumor compared to normal brain which indicated the 

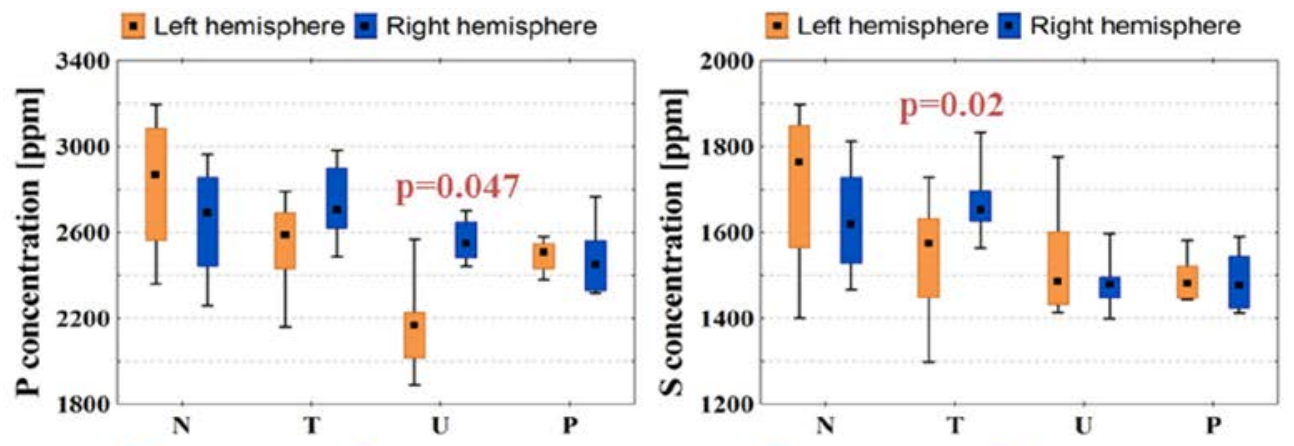

- Left hemisphere $\mathbf{E}$ Right hemisphere
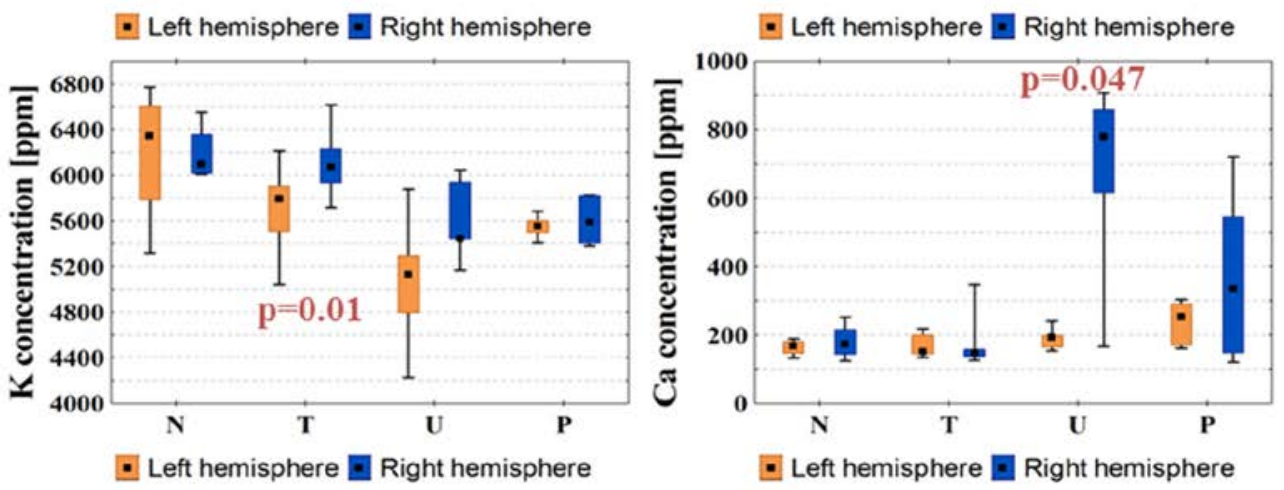

- Left hemisphere $\mathbf{D}$ Right hemisphere
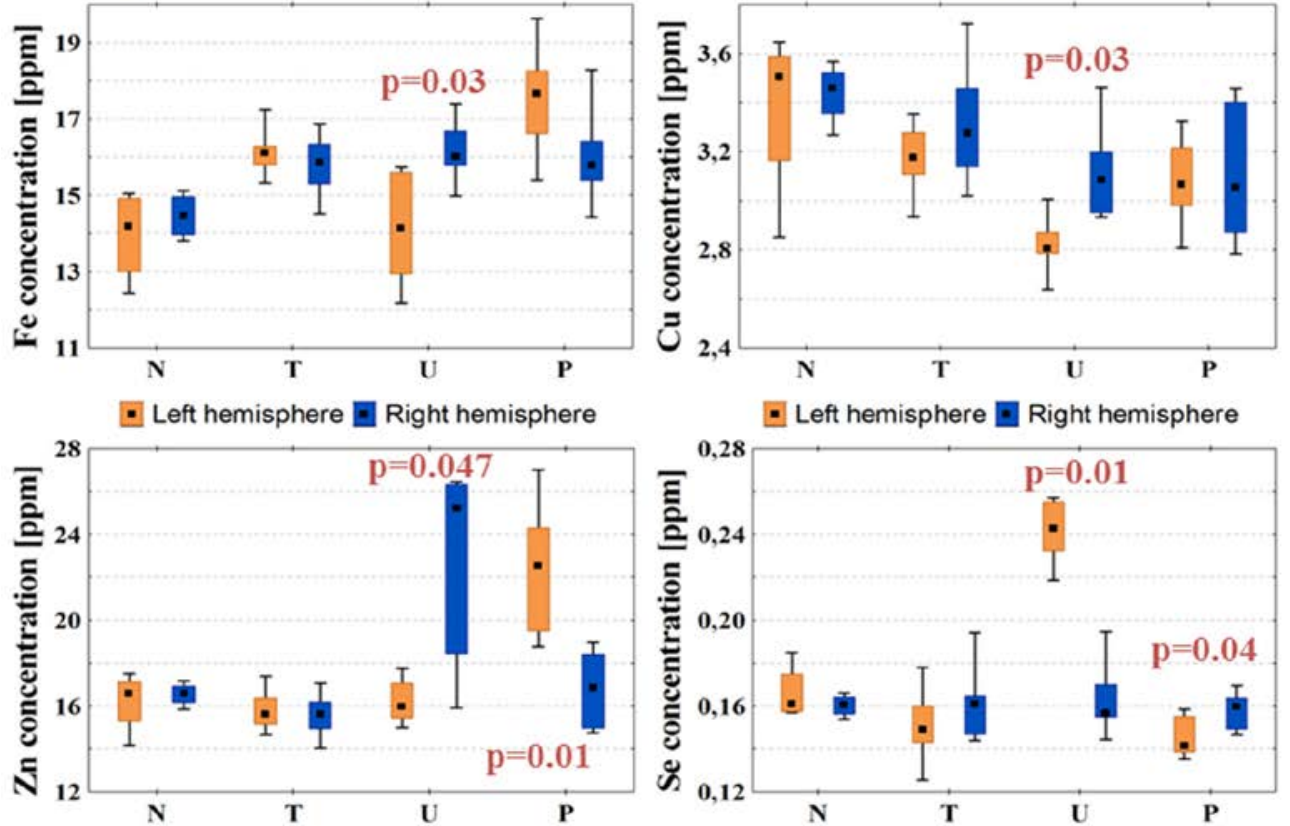

Figure 5. Concentrations of $\mathrm{P}, \mathrm{S}, \mathrm{K}, \mathrm{Ca}, \mathrm{Fe}, \mathrm{Cu}, \mathrm{Zn}$, and $\mathrm{Se}$ in both brain hemispheres determined for N, T, U, and $\mathrm{P}$ groups. Median, interquartile range, and minimal and maximal values of concentrations are indicated. Left and right hemispheres are marked with orange and blue colors, respectively. Statistically significant differences in elemental composition between the two hemispheres were identified using the Mann-Whitney test and are marked with $p$-values of $U$ test.

abnormal accumulation of this compound within the tumor. ${ }^{30}$ Andrasi et al. compared elemental composition of various regions of brain with and without tumor and did not find differences in phosphorus level between analyzed samples. ${ }^{31}$ Comparing the human samples taken from brains affected by tumors with different degrees of malignancy, Wandzilak et al. observed that the samples representing the highest malignant group (which included GBM samples) were characterized by decreased concentration of phosphorus. ${ }^{24}$ Our results seem to agree with the last mentioned report, as we noticed a significant decrease of phosphorus level in the left hemisphere taken from animals subjected to the implantation of the most invasive GBM cell line. What is more, for the rats representing $\mathrm{U}$ group, a significantly diminished level of the element within the implanted hemisphere was noticed compared to the intact one. Following the papers of Selverstone and Moulton ${ }^{28}$ as well as Hubesch et al., ${ }^{29}$ the lower level of phosphorus determined for $U$ group may suggest disorders in metabolism processes or decreased content of the important phosphorus compounds, like phospholipids, in tumor tissue. Such a conclusion is in agreement with our new unpublished data 
showing significantly diminished content of lipids within tumor mass compared to the neighboring tissues.

Our study did not reveal any significant anomalies in calcium and sulfur levels within left hemispheres taken from animals subjected to implantation of various GBM cells. However, rats from group $U$ presented increased calcium concentration within the right hemisphere compared to normal animals. What is more, in animals subjected to implantation of U87MG cells, the level of $\mathrm{Ca}$ in the right hemisphere exceeded that measured for the left one. Andrasi et al. did not observe the changes in calcium and sulfur levels between corresponding regions of brains with and without tumor. ${ }^{31}$ However, in the literature one can find also reports on decreased concentrations of these elements in brain tumor tissue with a high grade of malignancy. ${ }^{24}$ Calcium ions play a key role in cell signaling processes. It has been observed that calcium channels are characterized by altered expression in tumor tissues, including brain tumors with a high grade of malignancy. ${ }^{32}$ Due to a proven link between expression of calcium channels and homeostasis, angiogenesis, and growth of glioma tumors, they are considered as a potential target of cancer therapy. ${ }^{33}$ Xiao et al. observed that sulfur compounds $\left(\mathrm{Na}_{2} \mathrm{~S}\right)$ might have potential to increase the sensitivity of GBM cells (U87MG and T98G) to radiation therapy. ${ }^{34}$ Sulfur and selenium prevent DNA damage caused by copper and iron, which are the two metals involved in the production of highly reactive hydroxyl radicals. Compounds of sulfur and selenium have the ability to bind copper and iron and thus prevent the risk of DNA impairment. ${ }^{35}$ Wróbel et al. analyzed the content of sulfur compounds in tumor and normal brain tissue. They observed that compared to the other examined brain regions, malignant tumor tissue was characterized by an increased level of sulfane sulfur. $^{36}$

Potassium is an essential mineral participating in regulation of the water and acid balance in cells. It plays a key role in electrical impulse transmission, due to active transport of its ions across he cell membrane. ${ }^{37}$ Potassium is also involved in processes of cell death. It was shown that potassium ions suppress activity of a nuclease enzyme participating in apoptosis mechanisms, with complete inhibition at physiological potassium level found in living cells $(150 \mathrm{mM}) .{ }^{38}$ Eil et al. observed that cells under necrotic conditions release to the extracellular environment potassium ions, which suppress the immune response of T-cells in tumors. ${ }^{15}$ Results of various investigations indicate that potassium ion channels are abnormally expressed in glioma cells. Huang et al. found that ATP-sensitive potassium channels, overexpressed in glioma cells, regulate their proliferation. ${ }^{39}$ Suppression of some classes of potassium channels in U87MG cells resulted in significant improvement of therapy with TMZ, the main chemotherapy drug used to treat brain tumors including $\mathrm{GBM}^{40} \mathrm{Ru}$ et al. observed that blocking the voltage-gated potassium channels could induce apoptosis and inhibit proliferation of U87MG cells. $^{41}$ Szczerbowska-Boruchowska et al. and Wandzilak et al. compared concentrations of potassium within brain tumor samples of different stage of malignancy, but they did not find any significant differences between examined tumors. Nonetheless, they both determined potassium as the element of high importance for classification of brain tumors with respect to their malignancy. ${ }^{22,24}$ Also Andrasi et al. did not observed differences in potassium levels between regions of brain with and without tumor. ${ }^{31}$ Results of our experiment revealed a decrease of potassium level in both left and right brain hemispheres taken from rats subjected to implantation of U87MG cells. In animals from $P$ group, such an effect was found only for the intact hemisphere, while animals representing $\mathrm{T}$ group presented differences between the element accumulation within left and right hemispheres but the measured potassium concentrations in both hemispheres did not differ from the normal levels. Overexpression of potassium channels in glioma cells may increase the flow of the ions of the element into the extracellular environment. This, in turn, may facilitate the removal of the element from tumor volume and could explain diminished levels of potassium observed in implanted hemispheres of the brain.

Iron is a fundamental element in the human body, and it is crucial for the proper course of many biological processes ensuring growth and development of body cells. It is involved in oxygen transport, as a part of hemoglobin, and participates in nucleic acid synthesis. ${ }^{42}$ On the other hand, it may lead to DNA damage through reactive oxygen species formation. Therefore, regulation of iron levels is crucial for proper cell functioning. ${ }^{43}$ Both iron overload and its deficiency may play important roles in the mechanisms of carcinogenesis. ${ }^{44-46}$ Schonberg et al. ${ }^{47}$ observed that stem-like GBM cells are characterized by increased iron uptake compared to the remaining GBM and normal brain cells, and this mechanism may affect tumor proliferation. They also found that it was connected with increased expression and synthesis of iron storage protein ferritin and higher level of ferritin was positively correlated with malignancy grade of the tumor. ${ }^{47}$ As iron is involved in molecular processes of cell proliferation, including tumor cells, methods of its inhibition are tested as a promising strategy for GBM therapy. ${ }^{48}$ Andrasi et al. did not find differences in iron concentration between regions of brain with and without tumor. ${ }^{31}$ In turn, Wandzilak et al. observed a significant decrease of its content in samples of brain with high grade tumors compared to control tissues originating from non-brain-tumor patients. ${ }^{24}$ In our study, the animals subjected to the implantation of U87MG cells presented increased levels of iron in the right hemisphere compared to the normal rats as well as in relation to the corresponding left hemisphere. For the remaining experimental groups ( $\mathrm{T}$ and $\mathrm{P}$ ), we observed elevated iron levels compared to controls for both brain hemispheres, and no differences in the element accumulation was observed between implanted and intact hemispheres. Increased levels of iron found in rat brains may be connected with higher blood supply, which in the case of the implanted hemisphere could be a result of intensified tumorigenesis processes. It must be remembered that glioma tumors very often contain hemorrhaging regions, which also can lead to iron accumulation. The greater iron content in the intact hemisphere may also indicate its higher neuronal activity, caused by taking over some functions of the left hemisphere impaired as a result of tumor increase.

Copper constitutes a part of proteins involved in cell signaling and oxygen transport. Due to its high oxidative potential, it plays a crucial role in redox reactions. Its redox activity is important for enzyme action, but through reactiveoxygen species (ROS) production, it may be toxic for many important biomolecules. Disturbances of copper homeostasis in cells can lead to different pathologies. ${ }^{49}$ Research reports show that copper levels are elevated in many types of tumors, compared to controls, and targeting copper through chelation may be a potential direction for cancer therapy. ${ }^{50}$ Higher copper levels promote growth of cancer cells, while copper 
chelation results in antiproliferative effect. What is more, different copper concentrations may modulate cell metabolic pathways by influencing oxidative phosphorylation. ${ }^{51} \mathrm{Li}$ et al. showed that subcytotoxic copper levels induce senescence of U87 GBM cells, and this could be a potential direction for new anticancer therapy. ${ }^{52}$ Copper, due to the regulation of factors affecting growth of blood vessels, is an element involved in angiogenesis. Promoting angiogenesis, it may in turn influence the process of cancer development. ${ }^{53}$ Brem et al. observed that a low copper diet combined with penicillamine, a copper chelating agent, resulted in the reduction of proliferation and vascularity of glioma in the rabbit model of tumor. ${ }^{54}$ Jazayeri et al. found that the decrease of copper content in the diet of GBM patients led to the reduction of factors affecting angiogenesis processes. ${ }^{55}$ In turn, in the work of Pérès et al. increased accumulation of copper-labeled compounds in hypoxic areas of glioma was shown, and the authors suggested that this may be connected with redox processes and overexpression of cellular transporters of copper under hypoxic conditions. ${ }^{56}$ Yoshida et al. showed that higher copper concentrations are observed in malignant gliomas and metastatic brain tumor tissues compared to benign tumor and normal brain tissues. However, they did not specify if the analyzed malignant glioma corresponded to glioblastoma multiforme. ${ }^{57}$ Contrary to this, Szczerbowska-Boruchowska et al. and Wandzilak et al. did not indicate any correlations between $\mathrm{Cu}$ concentration and the degree of malignancy of brain tumor. However, they mentioned the element as significant for the tumor sample classification. ${ }^{22,24}$ Also Stojsavljević et al. did not observe any differences in $\mathrm{Cu}$ levels between brain malignant tumor samples, most of which were classified as GBM, and normal cerebral tissue. ${ }^{58}$ Denhardt et al. studied distributions of elements in different regions of GBM specimens. They observed that concentration of $\mathrm{Cu}$ was higher in brain tissue surrounding the tumor (peritumoral zone) than in the solid tumor. This indicates a possible heterogeneous distribution of copper in tissue affected by a tumor. ${ }^{21}$

Taking all this into account, the assessment of changes of $\mathrm{Cu}$ level in brain tumor tissue still remains unclear. The results we observed for lower invasiveness glioma cells ( $\mathrm{T}$ and $\mathrm{P}$ groups) seem to be in agreement with those of Stojsavljevic et al. who did not detect any differences between malignant and normal cerebral tissues. ${ }^{58}$ However, in case of the implantation of the most invasive U87MG cells, content of $\mathrm{Cu}$ within both hemispheres was significantly diminished compared to that in normal animals which may suggest some correlation between anomalies observed in the accumulation of the element and the degree of tumor malignancy. Further elemental study is necessary in this aspect and should involve topographic elemental analysis of tissues affected with glioma since copper distribution within tumor can be heterogeneous as was suggested in the study of Denhardt et al. ${ }^{21}$

Another micronutrient essential for proper functioning of living organisms is zinc. It is involved in activation and stabilization of a wide range of enzymes. Mainly in the ion form, zinc participates in synthesis and repair of DNA, apoptosis regulation, immune response and proliferation, differentiation, and signaling of cells. Due to its antioxidative property, zinc protects DNA and other biomolecules against damage caused by oxidative stress. ${ }^{59}$ Many reports prove that zinc is involved in the process of cancer cell death; however, this is a cell-specific effect. In some types of cancers, zinc has antiapoptotic properties, while for others it may induce cell death. ${ }^{60}$ Mehrian-Shai et al. found that p53 protein, which has cancer suppressing properties, is typically inactive in the U87MG cell line but can be activated through the addition of zinc. $^{61}$ Toren et al. discovered that the combination of zinc with TMZ enhances toxic effects of the drug on GBM cells in vitro, which manifests in reduction of cell proliferation and induction of apoptosis. Addition of $\mathrm{Zn}$ to TMZ resulted also in more effective inhibition of tumor growth in vivo than TMZ alone. ${ }^{62}$ Takeda et al. observed increased accumulation of zinc in brain tumor developing in rats subjected to C6 glioma cells implantation. The uptake of zinc in the tumor mass was clearly higher than in other regions of the brain. ${ }^{63,64}$ SzczerbowskaBoruchowska et al. and Wandzilak et al. included zinc in a group of elements with high significance for brain tumor classification with respect to their malignancy grade. ${ }^{22,24}$ What is more, Wandzilak et al. observed a higher concentration of $\mathrm{Zn}$ in tumor tissue compared to the control brain tissue. ${ }^{24}$ Andrasi et al. observed decreases in $\mathrm{Zn}$ concentration in various brain regions of humans diagnosed with GBM compared to the corresponding regions of the normal brain. ${ }^{31}$ According to Cilliers et al., this may be connected with intensified uptake of $\mathrm{Zn}$ by tumor cells from surrounding brain tissue. ${ }^{65}$ Stojsavljević et al. observed increased levels of zinc in samples of human brain tumor compared to a control tissue with a simultaneous decrease of its concentration in liquid samples, like serum and cerebrospinal fluid. ${ }^{58}$ The results of both Andrasi et al. and Stojsavljević et al. seem to suggest that increased accumulation of zinc within the tumor mass may be connected to uptake of the element from the tumor neighborhood. ${ }^{31,58}$ In turn, Denhardt et al. found that a higher concentration of $\mathrm{Zn}$ is specific rather for the tissue surrounding the tumor than for the tumor mass itself. They suggested that such localization of zinc may be evidence for the importance of this element for the tumor infiltration. ${ }^{21}$ In our study, abnormalities of $\mathrm{Zn}$ accumulation were observed in the left brain hemisphere of rats implanted with cells taken from a patient suffering from GBM. The animals presented higher content of the element compared to the normal rats. Additionally, for $\mathrm{P}$ group, the level of $\mathrm{Zn}$ in the implanted hemisphere was higher than that in the intact one. In turn, the opposite relation was found for the $\mathrm{U}$ group.

Selenium is an essential microelement included in various chemical compounds responsible for proper functioning of the body, such as antioxidative processes or immune response. ${ }^{66}$ It has high potential to prevent tumorigenesis including that developed in the brain. ${ }^{67} \mathrm{Zhu}$ et al. observed antiproliferative effect of selenium on human and rat glioblastoma cells. ${ }^{68}$ In another paper, the authors suggest that apoptotic death of tumor cells, initiated by selenium, may be connected with formation of oxygen free radicals. ${ }^{69}$ Rooprai et al. stated that selenium not only influences malignant human tumor cell death without affecting normal brain cells but can also reduce tumor invasiveness. ${ }^{70}$ Harmanci et al. observed different effects of selenium supplementation on human GBM cells, depending on the dose of selenium. Low doses of Se induced tumor cell proliferation, while high doses promoted death of GBM cells. ${ }^{71}$ Wang et al. showed that selenocysteine, an amino acid containing selenium, can inhibit the synthesis phase of the cell cycle of human glioma cells, blocking the process of DNA replication and resulting in decrease of cell proliferation. ${ }^{72}$ Research on potential use of selenium in the treatment of malignant brain tumors was also conducted. ${ }^{73-75}$ Zhang et al. observed a higher level of selenium in brain tumor regions 
compared to contralateral brain tissue of rats previously implanted with C6 glioma cells. ${ }^{76}$ Also Stojsavljevic et al. observed higher concentration of selenium in brain tumor tissue compared to control one. What is more, a decreased level of this element occurred in serum taken from patients with diagnosed malignant brain tumor. Authors suggested that tumor cells may be characterized by an increased demand for selenium. ${ }^{58}$ Results of our experiment showed abnormalities in brain selenium accumulation for $\mathrm{U}$ and $\mathrm{P}$ groups. For animals from $U$ group, the content of this element in the implanted hemisphere was elevated compared to the corresponding hemisphere taken from normal animals. The level of Se was also higher in the left than in the right hemisphere. The opposite relations were noticed for rats subjected to the patient-derived cell implantation. The results obtained for animals subjected to the implantation of the U87MG cells are in agreement with those obtained by Zhang et al. and Stojsavljevic et al. Such a conclusion, however, cannot be made in the case of tumor appearing as a result of patient-derived cell implantation.

Conclusions. GBM with its high aggressiveness and morbidity rate is the subject of many studies undertaken both for better understanding of its nature and for testing new therapeutic strategies. Animal models of glioma, applied in preclinical trials, are an invaluable tool in this kind of investigation. Due to the importance of different elements for tumor genesis and progression, confirmed by many studies, it seems necessary to perform elemental analysis of changes introduced through the developing tumor within the brain in various animal models of the disease. The largest number of elemental anomalies, both within implanted and intact hemispheres, was observed in rats subjected to implantation of U87MG cells. In turn, the lowest one was observed in animals after implantation of T98G cells. As the first cell line was characterized by the highest aggressiveness and the second by the lowest aggressiveness, we may try to connect the degree of elemental abnormalities with the extent of glioma invasiveness. The most of the observed elemental anomalies are specific for particular model of GBM; however the common hallmark of all experimental models of the disease is the elevated Fe level in the intact hemisphere. Within the implanted hemisphere, the level of this element was also higher for animals subjected to implantation of T98G and patientderived cells. In turn, Se presented model specific accumulation there. It occurred at the normal level after T98G cells implantation, at a decreased level in animals subjected to the implantation of patient-derived cells, and at an increased level in the case of the most invasive cell line, U87MG.

The bulk elemental analysis performed by us using the TXRF method gave information about changes in elemental composition occurring in the whole examined brain hemispheres. Based on the obtained results, the elements that may play a role in GBM pathogenesis were identified. However, as the distribution of elements in the tissues affected by the tumor may be heterogeneous, further studies are necessary. Especially helpful would be here topographic elemental analysis of the tumor mass and its surrounding areas providing more specific information on the contribution of particular elements in the pathogenesis and development of GBM.

\section{MATERIALS AND METHODS}

Cell Lines. Three glioblastoma cell lines were used for this study: T98G, U87MG, and patient-derived tumor cells. T98G and U87MG cell lines were purchased from ATCC company and cultured according to the manufacturer protocol. The first cell line is characterized as GBM type, while the second as "likely" glioblastoma. Both T98G and U87MG are human brain-derived cells with fibroblastoid or epithelial morphology, respectively. U87MG cell line is described by the manufacturer as tumorigenic, while T98G is described as nontumorigenic. Patient-derived cells originated from primary tumor of a patient diagnosed with GBM. They were isolated from a 23 year old woman in the Clinic of Neurosurgery and Neurotraumatology of University Hospital in Bydgoszcz according to the consent of the Bioethics Commission for the use of cellular material collected from patients in neurooncological operations (Decision no. 535/2017 from 13th June 2017, issued by the Bioethical Commission at University of Nicolaus Copernicus in Toruń). Written informed consent was obtained from the patient and all the procedures were in agreement with relevant guidelines and regulations.

Suspensions of glioma cells for implantation were prepared in the Department of Cell Biology of the Faculty of Biophysics, Biochemistry, and Biotechnology of Jagiellonian University (JU). Dulbecco's modified Eagle medium was used for preparation of the suspensions. The concentration of administered suspension was equal $5 \times 10^{4}$ cells $/ \mu \mathrm{L}$ for T98G cell line and patient-derived cells. For U87MG cell line, the concentration of cells was changed to $5 \times 10^{3}$ cells $/ \mu \mathrm{L}$ as our previous observations showing high mortality of Wistar rats after implantation at higher concentrations.

Experimental Animals. Animal husbandry and all animal-use experiments, previously approved by the second Local Institutional Animal Care and Use Committee (agreement no. 119/2016), were performed in accordance with the international standards in the Department of Neuroanatomy of the Institute of Zoology and Biomedical Research JU. The subjects of our study were male Wistar albino rats. The animals had free access to water and standard rodent food (Labofeed, Morawski). At 9 weeks of age, the rats were divided into four groups: N, T, U, and P. Each group consisted of 6 individuals. The animals from groups $\mathrm{T}$ and $\mathrm{U}$ were subjected to the implantation into the brain of the T98G and U87MG cell lines, respectively. Animals included in $\mathrm{P}$ group obtained primary tumor cells taken directly from a patient diagnosed with GBM, while the $\mathrm{N}$ group consisted of naive controls.

Implantations. The main part of the animal experiment was the transcranial implantation of GBM cells into the rat brain. The day before and on the day of surgery, the animals were weighed and given cyclosporine intravenously (Sandimmun $50 \mathrm{mg} / \mathrm{mL}$, Novartis Poland) at a dose of $10 \mathrm{mg} / \mathrm{kg}$ of body mass for immunosuppressive purposes. For the implantation, the animals were initially anesthetized in a desiccator filled with isoflurane (Aerrane, Baxter Poland). The same agent was administered by inhalation throughout the whole surgery, and its dose was monitored and adjusted to maintain general anesthesia. To precisely determine the place of implantation (Figure 6), the animals were immobilized in a stereotactic apparatus. The injection site was determined stereotaxically in the left hemisphere (coordinates antero-posterior, $-0.30 \mathrm{~mm}$; medio-lateral: $3.0 \mathrm{~mm}$; dorso-ventral: $5.0 \mathrm{~mm}$, Paxinos and Watson 1986). The first step was to drill a hole in the skull of the rat, where the needle (27 gauge needle on a Hamilton syringe) with the cell suspension was then placed. One minute after placing the needle, cell suspension in a volume of $5 \mu \mathrm{L}$ was introduced to the brain, and $3 \mathrm{~min}$ later the needle was slowly removed. Afterward, the wound was sutured with a stapler and disinfected. Animals woke up from anesthesia a few minutes after the end of the implantation procedure.

After surgery, the animals were intravenously administered cyclosporine (Novartis Poland) at a daily dose of $5 \mathrm{mg} / \mathrm{kg}$ of body mass. Additionally, for the first 7 days after glioma implantation, the rats were given an antibiotic (Sul-Tridin 24\%, ScanVet, Poland). The condition of animals was checked daily with particular attention to neurological deficits. The duration of the experiment, counted from the day of implantation, was 21 days for groups $\mathrm{N}, \mathrm{T}$, and P. In the case of the $\mathrm{U}$ group, due to very poor animal health revealed in deterioration of motor functions and body weight loss, and the 


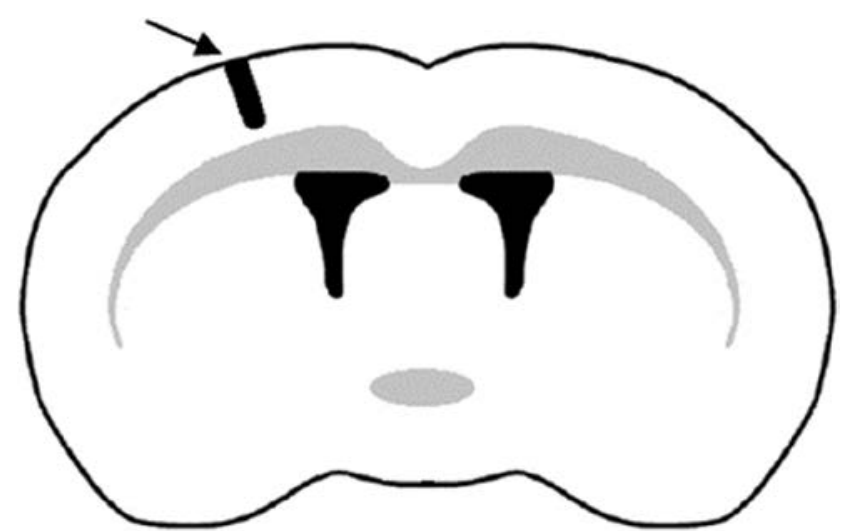

Figure 6. Location of the implantation site in the left cerebral hemisphere.

possibility of their premature death, the experiment was terminated 15 days after the surgery. Rats were sacrificed by intravenous administration of Euthasol-Vet (Euthasol vet. $400 \mathrm{mg} / \mathrm{mL}$, Le Vet B. V.) at doses appropriate to their weights. After perfusion with physiological saline, the brains were rapidly removed from the skulls and divided in two hemispheres, which were separately placed in the storage bags, immediately frozen in liquid nitrogen and stored in the freezer until further preparations.

Sample Preparation. TXRF method was applied to determine the concentrations of $\mathrm{P}, \mathrm{S}, \mathrm{K}, \mathrm{Ca}, \mathrm{Fe}, \mathrm{Cu}, \mathrm{Zn}$, and Se in both cerebral hemispheres. The elemental analysis using the TXRF spectrometry requires removal of the sample organic matrix and conversion of the sample from a solid (tissue) to a liquid form. For this purpose, microwave-assisted acid digestion was performed with the use of SpeedWave 4 digestion system (Berghof). Each hemisphere was placed in an individual Teflon vessel (DAP100) to which $5 \mathrm{~mL}$ of high purity nitric acid 65\% (Suprapur, Merck) was added. The brain samples were digested by using program "Tissue, blood", for which values of digestion parameters were as follows: temperature 50-190 ${ }^{\circ} \mathrm{C}$, pressure $0-30 \mathrm{bar}$, and power $0-870 \mathrm{~W}$. One digestion cycle lasted about $45 \mathrm{~min}$.

Apparatus and Measurement Conditions. Quantitative analysis using the TXRF method is based on the use of the internal standard and $1000 \mathrm{ppm}$ gallium solution (Gallium ICP standard in $\mathrm{HNO}_{3} 2-3 \% 1000 \mathrm{mg} / \mathrm{L}$ Ga Certipur, Merck was used for this purpose). Typically, $100 \mu \mathrm{L}$ of the internal standard was added to the entire sample volume (approximately $5 \mathrm{~mL}$ ) and mixed thoroughly. Six microliters of this solution was taken and spotted on a Super Frost (Menzel) glass slide, which was then dried on a heating plate. Three slides were made for each sample. The Rigaku Nanohunter II TXRF spectrometer was used for measurements. The apparatus allows for high-sensitivity elemental analysis of liquids at ultratrace (ppb) levels of elements. It is equipped with a $600 \mathrm{~W}$ X-ray tube with molybdenum anode, excitation energy of which is $17.44 \mathrm{keV}$ and silicon drift detector (SDD). The slides were placed in the 16-position cassette of the spectrometer, which allowed their automatic, sequential measurements. The acquisition time of a single slide was $1000 \mathrm{~s}$. The voltage of the tube was equal to $50 \mathrm{kV}$, while its current was $12 \mathrm{~mA}$. The measurements were performed at the glancing angle of $0.04^{\circ}$.

Quantitative Elemental Analysis. The concentration of each element $i$ in the analyzed sample was determined based on relationship 1:

$$
C_{i}=\frac{C_{\mathrm{IS}} N_{i}}{N_{\mathrm{IS}} S_{i}^{\mathrm{r}}}
$$

where $C_{i}$ is the concentration of the element $i$ in a sample [ppm], $C_{\mathrm{IS}}$ is the concentration of the added internal standard in a sample [ppm], $N_{i}$ is the number of counts for the element $i$ in the spectrum of the sample, $N_{\mathrm{IS}}$ is the number of counts for added internal standard in the spectrum of the sample, and $S_{i}^{\mathrm{r}}$ is the relative sensitivity of element $i$.

The relative sensitivities for analyzed elements were determined in the calibration process. Two standard solutions were used for this purpose: MERCK ICP multielement standard solution IV (23 elements diluted in nitric acid, $1000 \mathrm{mg} / \mathrm{L}$ ) and phosphorus singlecomponent standard $\left(10000 \mu \mathrm{g} / \mathrm{mL} \mathrm{P}\right.$ in $0.05 \% \mathrm{HNO}_{3}$ from $\mathrm{NH}_{4} \mathrm{H}_{2} \mathrm{PO}_{4}$ ) from High Purity Standards. The relative sensitivity coefficients of the elements, defined as the ratio of the sensitivity of a given element to the sensitivity of the internal standard, were determined based on formula 2 :

$$
S_{i}^{\mathrm{r}}=\frac{S_{i}}{S_{\mathrm{IS}}}=\frac{\frac{N_{i}^{\mathrm{s}}}{C_{i}^{s}}}{\frac{N_{\mathrm{IS}}^{\mathrm{s}}}{C_{\mathrm{IS}}^{\mathrm{s}}}}=\frac{C_{\mathrm{IS}}^{\mathrm{s}} N_{i}^{\mathrm{s}}}{N_{\mathrm{IS}}^{\mathrm{s}} C_{i}^{s}}
$$

where $S_{i}^{\mathrm{r}}$ is the relative sensitivity of the element $i, S_{i}$ is the sensitivity of the element $i, S_{\mathrm{IS}}$ is the sensitivity of the internal standard, $C_{i}^{\mathrm{s}}$ is the known concentration of element $i$ in the standard solution [ppm], $C_{\mathrm{IS}}^{\mathrm{s}}$ is the concentration of the internal standard in the standard solution [ppm], $N_{i}^{\mathrm{S}}$ is the number of counts of element $i$ in the spectrum of the standard solution, and $\mathrm{N}_{\mathrm{IS}}^{\mathrm{s}}$ is the number of counts for the internal standard in the spectrum of the standard solution.

Based on a calculated relative sensitivity, a calibration curve was determined and, together with its equation, presented in Figure 7.

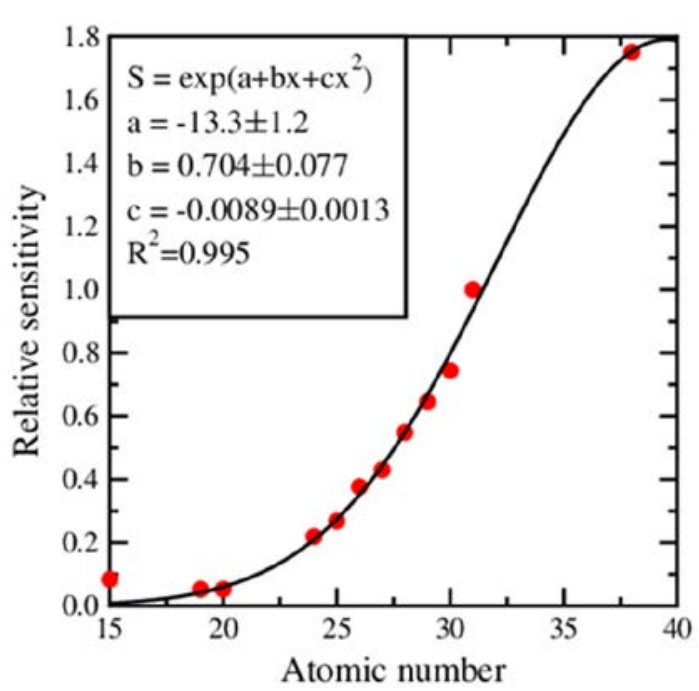

Figure 7. Relative sensitivity curve obtained from the measurements of Merck ICP multielement standard solution IV and phosphorus single-component standard from High Purity Standards.

Evaluation of limit of detection of elements in analyzed samples and precision of measurements was also performed. The limit of detection was calculated based on results obtained for all examined brain samples. The precision of measurements was calculated based on results for samples of normal brain. Depending on the time between measurements, intraday and interday precision were determined. Details concerning calculation of validation parameters and formulas used for this purpose are provided in Supporting Information.

\section{ASSOCIATED CONTENT}

\section{Supporting Information}

The Supporting Information is available free of charge at https://pubs.acs.org/doi/10.1021/acschemneuro.0c00648.

Methods to calculate limits of detection and precision (PDF) 


\section{AUTHOR INFORMATION}

\section{Corresponding Author}

Joanna Chwiej - AGH University of Science and Technology, Faculty of Physics and Applied Computer Science, Krakow 30-059, Poland; 이이.orid/0000-0002-3792-7876; Email: joanna.chwiej@fis.agh.edu.pl

\section{Authors}

Karolina Planeta - AGH University of Science and Technology, Faculty of Physics and Applied Computer Science, Krakow 30-059, Poland

Zuzanna Setkowicz - Jagiellonian University, Institute of Zoology and Biomedical Research, Krakow 31-007, Poland

Natalia Janik-Olchawa - AGH University of Science and Technology, Faculty of Physics and Applied Computer Science, Krakow 30-059, Poland

Katarzyna Matusiak - AGH University of Science and Technology, Faculty of Physics and Applied Computer Science, Krakow 30-059, Poland; 이이이.org/0000-00032211-8432

Damian Ryszawy - Jagiellonian University, Faculty of Biochemistry, Biophysics, and Biotechnology, Krakow 31-007, Poland

Agnieszka Drozdz - AGH University of Science and Technology, Faculty of Physics and Applied Computer Science, Krakow 30-059, Poland

Krzysztof Janeczko - Jagiellonian University, Institute of Zoology and Biomedical Research, Krakow 31-007, Poland

Beata Ostachowicz - AGH University of Science and Technology, Faculty of Physics and Applied Computer Science, Krakow 30-059, Poland

Complete contact information is available at:

https://pubs.acs.org/10.1021/acschemneuro.0c00648

\section{Author Contributions}

${ }^{\#}$ K.P. and Z.S. contributed equally. K.P. contributed to conceptualization, methodology, resources, investigation, validation, writing the original draft, and answers to the reviewers' remarks; Z.S. contributed to conceptualization, methodology, resources, supervision, and reviewing the manuscript; N.J.-O. contributed to methodology and investigation; K.M. contributed to methodology and investigation; D.R. contributed to methodology, resources, and reviewing the manuscript; A.D. contributed to methodology and investigation; K.J. contributed to reviewing manuscript; B.O. contributed to methodology and resources; J.C., as corresponding author, contributed to conceptualization, methodology, resources, validation, supervision, writing the original draft, and answers to the reviewers' remarks.

\section{Notes}

The authors declare no competing financial interest.

\section{ACKNOWLEDGMENTS}

This work was partially financed by the Polish Ministry of Science and Higher Education and by the Polish National Science Centre Grant No. UMO-2015/19/D/NZ3/00273. Karolina Planeta and Natalia Janik-Olchawa have been partially supported by the EU Project POWR.03.02.00-00-I004/16. Special thanks to Ph.D. Eng. Przemyslaw Wachniew from Faculty of Physics and Applied Computer Science, University of Science and Technology, in Krakow for providing access to chemical laboratory and sharing the mineralizer SpeedWave4.

\section{REFERENCES}

(1) Hanif, F., Muzaffar, K., Perveen, K., Malhi, S. M., and Simjee, S. U. (2017) Glioblastoma Multiforme: A Review of its Epidemiology and Pathogenesis through Clinical Presentation and Treatment. Asian Pac. J. Cancer Prev. 18 (1), 3-9.

(2) Czapski, B., Baluszek, S., Herold-Mende, C., and Kaminska, B. (2018) Clinical and immunological correlates of long term survival in glioblastoma. Wspolczesna Onkol. 22 (1A), 81-85.

(3) Holland, E. C. (2000) Glioblastoma multiforme: The terminator. Proc. Natl. Acad. Sci. U. S. A. 97 (12), 6242-6244.

(4) Urbańska, K., Sokołowska, J., Szmidt, M., and Sysa, P. (2014) Glioblastoma multiforme - an overview. Wspolczesna Onkol. 18 (5), 307-312.

(5) Henke, G., Meier, V., Lindner, L. H., Eibl, H., Bamberg, M., Belka, C., Budach, W., and Jendrossek, V. (2012) Effects of ionizing radiation in combination with Erufosine on T98G glioblastoma xenograft tumours: a study in NMRI nu/nu mice. Radiat. Oncol. 7, 172.

(6) Teicher, B. A., Menon, K., Álvarez, E., Galbreath, E., Shih, C., and Faul, M. M. (2001) Antiangiogenic and antitumor effects of a protein kinase Cbeta inhibitor in human T98G glioblastoma multiforme xenografts. Clin. Cancer Res. 7 (3), 634-40.

(7) Uchida, H., Marzulli, M., Nakano, K., Goins, W. F., Chan, J., Hong, C. S., Mazzacurati, L., Yoo, J. Y., Haseley, A., Nakashima, H., Baek, H., Kwon, H., Kumagai, I., Kuroki, M., Kaur, B., Chiocca, E. A., Grandi, P., Cohen, J. B., and Glorioso, J. C. (2013) Effective Treatment of an Orthotopic Xenograft Model of Human Glioblastoma Using an EGFR-retargeted Oncolytic Herpes Simplex Virus. Mol. Ther. 21 (3), 561-569.

(8) Lenting, K., Verhaak, R., Ter Laan, M., Wesseling, P., and Leenders, W. (2017) Glioma: experimental models and reality. Acta Neuropathol. 133 (2), 263-282.

(9) Flávio Key, F. K., Alves, M. J. F., Rocha, M. C., da Silva, R., ObaShinjo, S. M., and Marie, S. K. N. (2010) Xenograft Transplantation of Human Malignant Astrocytoma Cells Into Immunodeficient Rats: An Experimental Model of Glioblastoma. Clinics 65 (3), 305-309.

(10) Baklaushev, V. P., Kavsan, V. M., Balynska, O. V., Yusubalieva, G. M., Abakumov, M. A., and Chekhonin, V. P. (2012) New Experimental Model of Brain Tumors in Brains of Adult Immunocompetent Rats. Br. J. Med. Med. Res. 2 (2), 206-215.

(11) Biasibetti, E., Valazza, A., Capucchio, M. T., Annovazzi, L., Battaglia, L., Chirio, D., Gallarate, M., Mellai, M., Muntoni, E., Peira, E., Riganti, C., Schiffer, D., Panciani, P., and Lanotte, M. (2017) Comparison of Allogeneic and Syngeneic Rat Glioma Models by Using MRI and Histopathologic Evaluation. Comp. Med. 67 (2), 147156.

(12) Strojnik, T., Kavalar, R., and Lah, T. T. (2006) Experimental Model and Immunohistochemical Analyses of U87 Human Glioblastoma Cell Xenografts in Immunosuppressed Rat Brains. Anticancer Res. 26 (4B), 2887-2900.

(13) Bobko, A. A., Eubank, T., Driesschaert, B., Dhimitruka, I., Evans, J., Mohammad, R., Tchekneva, E. E., Dikov, M. M., and Khramtsov, V. (2017) Interstitial Inorganic Phosphate as a Tumor Microenvironment Marker for Tumor Progression. Sci. Rep. 7, 41233.

(14) Duan, F., Li, Y., Chen, L., Zhou, X., Chen, J., Chen, H., and Li, R. (2015) Sulfur inhibits the growth of androgen-independent prostate cancer in vivo. Oncol. Lett. 9 (1), 437-441.

(15) Eil, R., Vodnala, S. K., Clever, D., Klebanoff, C. A., Sukumar, M., Pan, J. H., Palmer, D. C., Gros, A., Yamamoto, T. N., Patel, S. J., Guittard, G. C., Yu, Z., Carbonaro, V., Okkenhaug, K., Schrump, D. S., Linehan, W. M., Roychoudhuri, R., and Restifo, N. P. (2016) Ionic immune suppression within the tumour microenvironment limits $\mathrm{T}$ cell effector function. Nature 537 (7621), 539-543.

(16) Callejón-Leblic, B., Arias-Borrego, A., Pereira-Vega, A., GómezAriza, J. L., and García-Barrera, T. (2019) The Metallome of Lung Cancer and its Potential Use as Biomarker. Int. J. Mol. Sci. 20 (3), 778.

(17) Jouybari, L., Saei Ghare Naz, M., Sanagoo, A., Kiani, F., Sayehmiri, F., Sayehmiri, K., and Hasanpour Dehkordi, A. (2018) 
Toxic elements as biomarkers for breast cancer: a meta-analysis study. Cancer Manage. Res. 10, 69-79.

(18) Silva, M. P., Soave, D. F., Ribeiro-Silva, A., and Poletti, M. E. (2012) Trace elements as tumor biomarkers and prognostic factors in breast cancer: a study through energy dispersive $\mathrm{x}$-ray fluorescence. BMC Res. Notes 5, 194.

(19) Zaichick, V., and Zaichick, S. V. (2018) Trace Elements of Expressed Prostatic Secretions as a Source for Biomarkers of Prostate Cancer. J. Clin. Res. Oncol. 1 (1), 1-7.

(20) Zoriy, M. V., Dehnhardt, M., Reifenberger, G., Zilles, K., and Becker, J. S. (2006) Imaging of $\mathrm{Cu}, \mathrm{Zn}, \mathrm{Pb}$ and $\mathrm{U}$ in human brain tumor resections by laser ablation inductively coupled plasma mass spectrometry. Int. J. Mass Spectrom. 257, 27-33.

(21) Dehnhardt, M., Zoriy, M. V., Khan, Z., Reifenberger, G., Ekström, T., Sabine Becker, J., Zilles, K., and Bauer, A. (2008) Element distribution is altered in a zone surrounding human glioblastoma multiforme. J. Trace Elem. Med. Biol. 22 (1), 17-23.

(22) Szczerbowska-Boruchowska, M., Lankosz, M., and Adamek, D. (2011) First step toward the 'fingerprinting' of brain tumors based on synchrotron radiation X-ray fluorescence and multiple discriminant analysis. JBIC, J. Biol. Inorg. Chem. 16 (8), 1217-1226.

(23) Lankosz, M. W., Grzelak, M., Ostachowicz, B., Wandzilak, A., Szczerbowska-Boruchowska, M., Wrobel, P., Radwanska, E., and Adamek, D. (2014) Application of the total reflection X-ray fluorescence method to the elemental analysis of brain tumors of different types and grades of malignancy. Spectrochim. Acta, Part B 101, 98-105.

(24) Wandzilak, A., Czyzycki, M., Radwanska, E., Adamek, D., Geraki, K., and Lankosz, M. (2015) X-ray fluorescence study of the concentration of selected trace and minor elements in human brain tumours. Spectrochim. Acta, Part B 114, 52-57.

(25) Brown, R. B., and Razzaque, M. S. (2018) Endocrine Regulation of Phosphate Homeostasis, Textbook of Nephro-Endocrinology, pp 539-548, Elsevier, DOI: 10.1016/B978-0-12-8032473.00032-5.

(26) Ardito, F., Giuliani, M., Perrone, D., Troiano, G., and Muzio, L. L. (2017) The crucial role of protein phosphorylation in cell signaling and its use as targeted therapy (Review). Int. J. Mol. Med. 40 (2), 271-280.

(27) Selverstone, B., and Solomon, A. K. (1948) Radioactive isotopes in the study of intracranial tumors. Preliminary report of methods and results. Trans. Am. Neurol. Assoc. 73, 115-119.

(28) Selverstone, B., and Moulton, M. J. (1957) The phosphorus metabolism of gliomas: a study with radioactive isotopes. Brain 80 (3), 362-375.

(29) Hubesch, B., Sappey-Marinier, D., Roth, K., Meyerhoff, D. J., Matson, G. B., and Weiner, M. W. (1990) P-31 MR spectroscopy of normal human brain and brain tumors. Radiology 174 (2), 401-409.

(30) Srivastava, N. K., Pradhan, S., Gowda, G. A. N., and Kumar, R. (2009) In vitro, high-resolution $1 \mathrm{H}$ and 31P NMR based analysis of the lipid components in the tissue, serum, and CSF of the patients with primary brain tumors: one possible diagnostic view. NMR Biomed. 23, 113-122.

(31) Andrási, E., Suhajda, M., Sáray, I., Bezúr, L., Ernyei, L., and Réffy, A. (1993) Concentration of elements in human brain: glioblastoma multiforme. Sci. Total Environ. 139-140, 399-402.

(32) Morrone, F. B., Gehring, M. P., and Nicoletti, N. F. (2016) Calcium Channels and Associated Receptors in Malignant Brain Tumor Therapy. Mol. Pharmacol. 90 (3), 403-409.

(33) Li, S., and Ding, X. (2017) TRPC Channels and Glioma. Adv. Exp. Med. Biol. 976, 157-165.

(34) Xiao, A. Y., Maynard, M. R., Piett, C. G., Nagel, Z. D., Alexander, J. S., Kevil, C. G., Berridge, M. V., Pattillo, C. B., Rosen, L. R., Miriyala, S., and Harrison, L. (2019) Sodium sulfide selectively induces oxidative stress, DNA damage, and mitochondrial dysfunction and radiosensitizes glioblastoma (GBM) cells. Redox Biol. 26, 101220.

(35) Zimmerman, M. T., Bayse, C. A., Ramoutar, R. R., and Brumaghim, J. L. (2015) Sulfur and selenium antioxidants: Challenging radical scavenging mechanisms and developing struc- ture-activity relationships based on metal binding. J. Inorg. Biochem. $145,30-40$.

(36) Wróbel, M., Czubak, J., Bronowicka-Adamska, P., Jurkowska, H., Adamek, D., and Papla, B. (2014) Is Development of High-Grade Gliomas Sulfur-Dependent? Molecules 19 (12), 21350-21362.

(37) Kowey, P. R. (2002) The Role of Potassium, Women's Health and Menopause, pp 151-157, Springer, Boston, MA, DOI: 10.1007/ 978-1-4615-1061-1 18.

(38) Hughes, F. M., Jr., and Cidlowski, J. A. (1999) Potassium is a critical regulator of apoptotic enzymes in vitro and in vivo. $A d v$. Enzyme Regul. 39, 157-171.

(39) Huang, L., Li, B., Li, W., Guo, H., and Zou, F. (2009) ATPsensitive potassium channels control glioma cells proliferation by regulating ERK activity. Carcinogenesis 30 (5), 737-744.

(40) Sales, T. T., Resende, F. F. B., Chaves, N. L., Titze-De-Almeida, S. S., Báo, S. N., Brettas, M. L., and Titze-De-Almeida, R. (2016) Suppression of the Eag1 potassium channel sensitizes glioblastoma cells to injury caused by temozolomide. Oncol. Lett. 12 (4), 25812589.

(41) Ru, Q., Tian, X., Pi, M., Chen, L., Yue, K., Xiong, Q., Ma, B., and $\mathrm{Li}, \mathrm{C}$. (2015) Voltage-gated $\mathrm{K}+$ channel blocker quinidine inhibits proliferation and induces apoptosis by regulating expression of microRNAs in human glioma U87-MG cells. Int. J. Oncol. 46 (2), $833-840$.

(42) Chen, Y., Fan, Z., Yang, Y., and Gu, C. (2019) Iron metabolism and its contribution to cancer (Review). Int. J. Oncol. 54, 1143-1154.

(43) Manz, D. H., Blanchette, N. L., Paul, B. T., Torti, F. M., and Torti, S. V. (2016) Iron and cancer: recent insights. Ann. N. Y. Acad. Sci. 1368 (1), 149-161.

(44) Huang, X. (2003) Iron overload and its association with cancer risk in humans: evidence for iron as a carcinogenic metal. Mutat. Res., Fundam. Mol. Mech. Mutagen. 533 (1-2), 153-171.

(45) Eckard, J., Dai, J., Wu, J., Jian, J., Yang, Q., Chen, H., Costa, M., Frenkel, K., and Huang, X. (2010) Effects of cellular iron deficiency on the formation of vascular endothelial growth factor and angiogenesis. Iron deficiency and angiogenesis. Cancer Cell Int. 10, 28.

(46) Hossein Davoodi, S., Jamshidi-Naeini, Y., Esmaeili, S., Sohrabvandi, S., and Mortazavian, A. M. (2016) The Dual Nature of Iron in Relation to Cancer: A Review. Iran. J. Cancer Prev. 9, No. e5494.

(47) Schonberg, D. L., Miller, T. E., Wu, Q., Flavahan, W. A., Das, N. K., Hale, J. S., Hubert, C. G., Mack, S. C., Jarrar, A. M., Karl, R. T., Rosager, A. M., Nixon, A. M., Tesar, P. J., Hamerlik, P., Kristensen, B. W., Horbinski, C., Connor, J. R., Fox, P. L., Lathia, J. D., and Rich, J. N. (2015) Preferential Iron Trafficking Characterizes Glioblastoma Stem-like Cells. Cancer Cell 28 (4), 441-455.

(48) Gaur, K., Vázquez-Salgado, A. M., Duran-Camacho, G., Dominguez-Martinez, I., Benjamín-Rivera, J. A., Fernández-Vega, L., Sarabia, L. C., García, A. C., Pérez-Deliz, F., Román, J. A. M., VegaCartagena, M., Loza-Rosas, S. A., Acevedo, X. R., and Tinoco, A. D. (2018) Iron and Copper Intracellular Chelation as an Anticancer Drug Strategy. Inorganics 6, 126.

(49) Denoyer, D., Masaldan, S., La Fontaine, S., and Cater, M. A. (2015) Targeting copper in cancer therapy: 'Copper That Cancer'. Metallomics 7 (11), 1459-1476.

(50) Gupte, A., and Mumper, R. J. (2009) Elevated copper and oxidative stress in cancer cells as a target for cancer treatment. Cancer Treat. Rev. 35 (1), 32-46.

(51) Ishida, S., Andreux, P., Poitry-Yamate, C., Auwerx, J., and Hanahan, D. (2013) Bioavailable copper modulates oxidative phosphorylation and growth of tumors. Proc. Natl. Acad. Sci. U. S. A. 110 (48), 19507-19512.

(52) Li, Y., Hu, J., Guan, F., Song, L., Fan, R., Zhu, H., Hu, X., Shen, E., and Yang, B. (2013) Copper induces cellular senescence in human glioblastoma multiforme cells through downregulation of Bmi-1. Oncol. Rep. 29 (5), 1805-1810.

(53) Xie, H., and Kang, Y. (2009) Role of Copper in Angiogenesis and Its Medicinal Implications. Curr. Med. Chem. 16 (10), 13041314. 
(54) Brem, S. S., Zagzag, D., Tsanaclis, A. M., Gately, S., Elkouby, M. P., and Brien, S. E. (1990) Inhibition of angiogenesis and tumor growth in the brain. Suppression of endothelial cell turnover by penicillamine and the depletion of copper, an angiogenic cofactor. Am. J. Pathol. 137 (5), 1121-1142.

(55) Jazayeri, S., Feli, A., Bitaraf, M. A., Dodaran, M. S., Alikhani, M., and Hosseinzadeh-Attar, M. J. (2016) Effects of Copper Reduction on Angiogenesis-Related Factors in Recurrent Glioblastoma Cases. Asian Pac. J. Cancer Prev. 17 (10), 4609-4614.

(56) Pérès, E. A., Toutain, J., Paty, L. P., Divoux, D., Ibazizène, M., Guillouet, S., Barré, L., Vidal, A., Cherel, M., Bourgeois, M., Bernaudin, M., and Valable, S. (2019) 64Cu-ATSM/64Cu-Cl2 and their relationship to hypoxia in glioblastoma: a preclinical study. EJNMMI Res. 9, 114.

(57) Yoshida, D., Ikeda, Y., and Nakazawa, S. (1993) Quantitative analysis of copper, zinc and copper/zinc ratio in selected human brain tumors. J. Neuro-Oncol. 16, 109-115.

(58) Stojsavljević, A., Vujotić, L., Rovčanin, B., Borković-Mitić, S., Gavrović-Jankulović, M., and Manojlović, D. (2020) Assessment of trace metal alterations in the blood, cerebrospinal fluid and tissue samples of patients with malignant brain tumors. Sci. Rep. 10, 3816.

(59) Skrajnowska, D., and Bobrowska-Korczak, B. (2019) Role of Zinc in Immune System and Anti-Cancer Defense Mechanisms. Nutrients 11 (10), 2273.

(60) Franklin, R. B., and Costello, L. C. (2009) The important role of the apoptotic effects of zinc in the development of cancers. J. Cell. Biochem. 106 (5), 750-757.

(61) Mehrian-Shai, R., Yalon, M., Simon, A. J., Eyal, E., Pismenyuk, T., Moshe, I., Constantini, S., and Toren, A. (2015) High metallothionein predicts poor survival in glioblastoma multiforme. BMC Med. Genomics 8, 68.

(62) Toren, A., Pismenyuk, T., Yalon, M., Freedman, S., Simon, A. J., Fisher, T., Moshe, I., Reichardt, J. K. V., Constantini, S., Mardor, Y., Last, D., Guez, D., Daniels, D., Assoulin, M., and Mehrian-Shai, R. (2016) Zinc enhances temozolomide cytotoxicity in glioblastoma multiforme model systems. Oncotarget 7 (46), 74860-74871.

(63) Takeda, A., Tamano, H., Enomoto, S., and Oku, N. (2001) Zinc-65 Imaging of Rat Brain Tumors. Cancer Res. 61 (13), 50655069.

(64) Takeda, A., Tamano, H., and Oku, N. (2003) Alteration of zinc concentrations in the brain implanted with C6 glioma. Brain Res. 965 (1-2), 170-173.

(65) Cilliers, K., Muller, C. J. F., and Page, B. J. (2020) Trace Element Concentration Changes in Brain Tumors: A Review. Anat. Rec. 303 (5), 1293-1299.

(66) Mehdi, Y., Hornick, J.-L., Istasse, L., and Dufrasne, I. (2013) Selenium in the Environment, Metabolism and Involvement in Body Functions. Molecules 18 (3), 3292-3311.

(67) Yakubov, E., Buchfelder, M., Eyüpoglu, I. Y., and Savaskan, N. E. (2014) Selenium Action in Neuro-Oncology. Biol. Trace Elem. Res. 161 (3), 246-254.

(68) Zhu, Z., Kimura, M., Itokawa, Y., Nakatsu, S., Oda, Y., and Kikuchi, H. (1995) Effect of selenium on malignant tumor cells of brain. Biol. Trace Elem. Res. 49, 1-7.

(69) Zhu, Z., Kimura, M., Itokawa, Y., Aoki, T., Takahashi, J. A., Nakatsu, S., Oda, Y., and Kikuchi, H. (1996) Apoptosis induced by selenium in human glioma cell lines. Biol. Trace Elem. Res. 54 (2), 123-134.

(70) Rooprai, H. K., Kyriazis, I., Nuttall, R. K., Edwards, D. R., Zicha, D., Aubyn, D., Davies, D., Gullan, R., and Pilkington, G. J. (2007) Inhibition of invasion and induction of apoptosis by selenium in human malignant brain tumour cells in vitro. Int. J. Oncol. 30 (5), $1263-1271$.

(71) Harmanci, D., Erbayraktar, Z., Sayin, O., and Guner, G. A. (2017) In Vitro effects of Selenium on Human Glioblastoma Multiforme Cell Lines: A Preliminary Study. ACTA Clin. Croat. 56, $48-57$.

(72) Wang, K., Fu, X., Li, Y., Hou, Y., Yang, M., Sun, J., Yi, S., Fan, C., Fu, X., Zhai, J., and Sun, B. (2016) Induction of S-Phase Arrest in
Human Glioma Cells by Selenocysteine, a Natural SeleniumContaining Agent Via Triggering Reactive Oxygen Species-Mediated DNA Damage and Modulating MAPKs and AKT Pathways. Neurochem. Res. 41 (6), 1439-1447.

(73) da Cruz, E. H. G., Silvers, M. A., Jardim, G. A. M., Resende, J. M., Cavalcanti, B. C., Bomfim, I. S., Pessoa, C., de Simone, C. A., Botteselle, G. V., Braga, A. L., Nair, D. K., Namboothiri, I. N. N., Boothman, D. A., and da Silva Júnior, E. N. (2016) Synthesis and antitumor activity of selenium-containing quinone-based triazoles possessing two redox centres, and their mechanistic insights. Eur. J. Med. Chem. 122, 1-16.

(74) Xu, B., Zhang, Q., Luo, X., Ning, X., Luo, J., Guo, J., Liu, Q., Ling, G., and Zhou, N. (2020) Selenium nanoparticles reduce glucose metabolism and promote apoptosis of glioma cells through reactive oxygen species-dependent manner. NeuroReport 31 (3), 226-234.

(75) Ertilav, K., Nazıroğlu, M., Ataizi, Z. S., and Braidy, N. (2019) Selenium Enhances the Apoptotic Efficacy of Docetaxel Through Activation of TRPM2 Channel in DBTRG Glioblastoma Cells. Neurotoxic. Res. 35 (4), 797-808.

(76) Zhang, Z., Miyatake, S., Saiki, M., Asahi, M., Yukawa, H., Toda, H., Kikuchi, H., Yoshimura, S., and Hashimoto, N. (2000) Selenium and Glutathione Peroxidase mRNA in Rat Glioma. Biol. Trace Elem. Res. 73 (1), 67-76. 